\title{
EL ASPECTO FÍSICO DE LOS PERSONAJES DEL TEATRO DE SAMUEL BECKETT.
}

\author{
Miguel Ibáñez Rodríguez* \\ Universidad de La Rioja
}

\begin{abstract}
RESUMEN.-En el presente artículo se lleva a cabo un pormenorizado análisis del aspecto físico de los personajes del teatro de S. Beckett. Se estudia su manera de vestir, el maquillaje, el peinado, su edad y sus deficiencias físicas a partir del método semiológico teatral de T. Kowzan. Al final, además de hacer alguna aportación metodológica, establecemos el personaje tipo. Éste corresponde a una persona de edad avanzada, con frecuencia con alguna deficiencia física, que viste mal, escasamente maquillada y que descuida sus cabellos. Su cuerpo es poco expresivo y nada individualizado.
\end{abstract}

RÉSUMÉ.- L'objetif de cet article est celui d'analyser l'aspect physique des personnages du théâtre de S. Beckett. On étudie les vêtements, le maquillage, la coiffure, l'âge et les déficiences physiques à partir de la méthode sémiologique de T. Kowzan. En plus de faire un petit apport méthodologique, on établie le personnage type.Celui-ciest une personne âgée, mal habillée, très peu maquillée, les cheveux en désordre et, presque toujours, avec des déficiences physiques. Son corps pas individualisé par rapport aux autres personnages est très peu expressif.

\section{INTRODUCCIÓN}

El autor de este artículo pretende realizar un análisis del aspecto físico de los personajes del teatro de Samuel Beckett. Para ello se recurre al método de análisis semiótico teatral propuesto por Tadeusz Kowzan ${ }^{1}$. Y, concretamente, al conjunto de sistemas de signos que establece para toda representación. Lógicamente, nos ajustaremos únicamente a aquellos que conciernen al aspecto externo del actor; no incluyendo los referentes a la expresión corporal, ni los correspondientes al texto pronunciado. Son

*Licenciado en Filología Francesa. Area de Francés, Departamento de Filologías Modemas, Universidad de La Rioja, Magisterio s/n, 26004 Logroño.

1. Littérature et spectacle, La Haya, Mouton, 1975. Nos referimos, ante todo, a la tercera parte de esta obra. 
los siguientes: maquillaje, peinado y vestuario. Tenemos, por lo tanto, tres sistemas de signos que nos van a permitir vertebrar y estructurar el objetivo que nos hemos propuesto.

La aplicación de dicho método al caso concreto planteado implica algunas modificaciones que a continuación señalamos. Jenaro Talens ${ }^{2}$, por su parte, revisa los trece sistemas establecidos por el autor citado y sugiere algunas objeciones. Entre otras y refiriéndonos a las que nos interesan, señala que "ciertas oposiciones en ocasiones son difíciles de mantener, por ejemplo, las propuestas entre mímica-gesto, maquillajepeinado..." 3 . Si a esto añadimos las exigencias de la producción teatral beckettiana, la introducción de nuevos sistemas de signos queda perfectamente justificada. De manera que además de los sistemas ya citados, tendremos en cuenta dos más: la edad y las deficiencias físicas. Ambos son de vital importancia y contribuyen notablemente a la hora de perfilar el cuerpo de los personajes. Como tendremos ocasión de ver, la mayoría de los personajes son de edad avanzada y, en ellos, son frecuentes los defectos físicos.

Una vez establecidos los sistemas, analizaremos los signos visuales que componen cada uno de ellos. Adoptando, al igual que Kowzan, "le schème saussurien signifié et signifiant, deux composants du signe (le signifié correspond au contenu, le signifiant à l'expression)" 4 .

Planteadas las líneas generales, nos corresponde ahora anotar algunas cuestiones puramente formales. El artículo se centra en la producción teatral beckettiana desde su inicio con En attendant Godot, escrita en 1952, hasta Quoi où que data de 1983. Al final aparece una detallada relación de las obras estudiadas, por orden cronológico de escritura y con la distribución de los personajes. De esta manera se evitará cualquier problema, ya que los citamos sin señalar la obra; sólo se hace cuando son designados por una letra, con el fin de evitar confusiones.

Dado el carácter del trabajo, nos ceñimos exclusivamente a las acotaciones escénicas. Completadas con la consulta de los cuadernos de las puestas en escena de Beckett ${ }^{5}$, las representaciones vistas por el autor del artículo y las referencias indirectas al tema elegido que aparecen en los propios diálogos.

Siempre que se localiza a los personajes o a cualquier elemento del escenario se hace, al igual que Beckett en las acotaciones, tomando como referencia al espectador.

\section{VESTUARIO}

En general, los personajes beckettianos visten mal. Estragon, aparte de ir descalzo durante casi toda la obra, lleva harapos y sujeta sus pantalones con una cuerda ${ }^{6}$. Su compañero Vladimir presenta parecidas maneras, aunque algo mejores: lleva chaqueta ${ }^{7}$.

\footnotetext{
2. Elementos para una semiótica del texto artístico: poesía narrativa, teatro, cine, Madrid, Cátedra, 1980.

3. Ibid., p. 172.

4. Littérature et spectacle, op. cit., p. 179

5. Estos están recogidos en el Capitulo V de Revue d'Esthétique.Samuel Beckett, Numéro spécial hors série, Toulouse Cedex, Editions Privat, 1986.

6. En attendant Godot, Paris, Les Editions de Minuit, 1952; p. 14/p. 132

7. Ibid., p. 99.
} 
Sus ropas dejan a las claras que se trata de dos vagabundos. Es el único caso en que gracias a la indumentaria se puede establecer, sin lugar a dudas, a qué clase social pertenecen. Krapp viste buenas prendas, sin embargo su estado es lamentable. Su pantalón y chaleco, con cuatro bolsillos, son "d"un noir pisseux". Su camisa blanca está mugrienta y sus botines blancos, ennegrecidos ${ }^{8}$.

Hay personajes ataviados de tal manera que cubren todo su cuerpo e incluso su rostro. Flo, Vi y $\mathrm{Ru}$, con sus largos abrigos abotonados hasta el cuello y con sus sombreros "à bords assez larges pour que les visages soient dans l'ombre", presentan idéntico aspecto ${ }^{9}$. Sus ropas las desdibujan y uniforman, despersonalizándolas físicamente. Se diferencian únicamente por el color de sus abrigos: violeta oscuro el de $\mathrm{Ru}$, rojo oscuro el de Vi y amarillo oscuro el de Flo. Entre los dos personajes de Impromptu d'Ohio ni siquiera se establece esta diferencia. Ambos portan un "long manteau noir"10. Ni tampoco en Quoi oú donde Bam, Bem, Bim y Bom llevan un "même longue robe gris"11.

La amplia chilaba con capuchón del Auditor de Pas moi quien, además, está débilmente iluminado, no permite establecer con exactitud si se trata de un hombre o de una mujer. Beckett señala: "sexe indéterminé" 12. La bata andrajosa de May no deja ver sus pies que es la parte más iluminada de su cuerpo. Su rostro en la penumbra apenas se aprecia ${ }^{13}$. P de Catastrophe lleva, al comenzar la obra, una bata negra hasta los tobillos y un amplio sombrero que le cubre parcialmente el rostro ${ }^{14}$.

Tadeusz Kowzan, al hablar del vestuario, señala lo siguiente:

Au théâtre, il est le moyen le plus extérieur, le plus conventionnel de définir l'individu humain. Vériste ou allusif, le costume peut signifier le sexe, l'âge, l'appartenance à une classe sociale, la profession, une position sociale ou hiérarchique particulière (roi, pape), la nationalité, la religion, il détermine parfois une personnalité historique. Dans les limites de chacune de ces catégories, et aussi au dehors d'elles, le costume est capable d'exprimer toute sorte de nuances, comme la situation matérielle du personnage, ses goûts, certains traits de son caractère ${ }^{15}$.

Exceptuando a Vladimir y Estragon, en los demás casos no ocurre nada de esto. Su indumentaria no sirve ni para caracterizarlos, ni para definirlos, mas bien para todo lo contrario. Los indetermina y difumina y, además, borra las posibles diferencias entre ellos. En todo caso habría que decir que los define no definiéndolos. Las funciones de

8. La dernière bande, París, Les Editions de Minuit, 1959; pp. 7.8.

9. Comédie et actes divers. Va-et-vient, Acte sans paroles I et II, Souffle, París, Les Editions de Minuit, 1972; p. 43.

10. Catastrophe et autres dramaticules. Cettefois, Solo, Berceuse, Impromptud'Ohio, Quoi où, Paris, Les Editions de Minuit, 1986; p. 59.

11. Ibid., p. 85.

12. Oh les beaux jours suivi de Pas moi, París, Les Editions de Minuit, 1963-1974; p. 81.

13. Pas suivi de quatre esquisses (Fragment de théâtre I et II), París, Les Editions de Minuit, 1978; p. 7.

14. Catastrophe et autres..., op. cit., p. 72.

15. Kowzan, op. cit., p. 195. 
la ropa, señaladas por este autor, no aparecen, por lo tanto, en el teatro que nos ocupa.

Contrariamente a lo que ocurre en los ejemplos anteriores, en Winnie, Willie y $F$ de Berceuse se advierte cierta elegancia. La primera viste una blusa escotada que deja hombros y brazos desnudos y resalta su abundante pecho. Lleva bolso y sombrilla y, ya avanzado el comienzo de la obra, se coloca un sombrero "très bibi, plume froissée" ${ }^{16}$. Aparte de éste no hay más casos en el que la ropa contribuya a resaltar el físico del personaje. La única vez que Willie sale completamente de su refugio, to hace con uniforme de gala. En claro contraste con el sombrero de paja "garni d'un ruban bicolore" que muestra al asomar su cabeza por detrás del montículo ${ }^{17}$. Este sombrero desentona con las elegancia de Winnie y llega a ridiculizarla en el caso de su esposo. Tengamos en cuenta también que su salida se produce a gatas. Flleva un vestido de noche, sin escote y con mangas largas, oponiéndose al "atrevimiento" de Winnie, adornado con lentejuelas que brillan con el balanceo de la mecedora y acompañado de un sombrero "incongru, posé de guingois, garni de frivolités" ${ }^{18}$. Este desempcña la misma función que el de Willie, ya que debido a su incongruencia desentona con la elegancia del vestido. Por lo tanto, no se puede afirmar que estos tres personajes vistan elegantemente. Unicamente podremos decir que llevan prendas elegantes cuya combinación no es acertada, llegando incluso a ser ridícula.

Acabamos de ver la elegancia de ciertos personajes escarnecida. A veces, la manera de vestir ridiculiza a los personajes. Ejemplo de ello son Estragon, Krapp y sobre todo P. Si a las peculiares formas de vestir del primero añadimos que Vladimir le remanga los pantalones ${ }^{19}$, tenemos la imagen de un personaje entre el bufón y el payaso. El pantalón ajustado y demasiado corto y el sorprendente par de botines del 48 , muy estrechos y puntiagudos, del protagonista de La dernière bande manifiestan un aspecto que raya lo cómico y lo ridículo ${ }^{20}$.

$P$ aparece, al comienzo de la obra, sobre un pedestal, descalzo, con bata y amplio sombrero $^{21}$. A, cumpliendo órdenes de $\mathrm{M}$, va modificando su aspecto a lo largo de toda la obra. Además de los cambios de posturas, que no nos interesan ahora, realiza otros en su vestimenta. Le quita la bata y el sombrero, quedándose con un "vieux pyjama gris". Después le remanga, por encima de la rodilla, las perneras de éste ${ }^{22}$. Siguiendo el mismo procedimiento que con Estragon se consigue aumentar considerablemente el grado de ridiculez que ya presenta al comienzo de Catastrophe.

Considerando la vestimenta de algunos personajes, podemos situarlos o bien en el momento inmediatamente anterior a acostarse o bien en el que sigue al levantarse de la cama. Hamm aparece "en robe de chambre", con gorro de ficltro y zapatillas después que Clov "enlève le drap qui le recouvre"23. Las dudas sobre si esta acción significa

16. Oh les beaux jours suivi de..., op. cit., pp. 11-12/pp. 20-21.

17. Ibid., p. 73/p. 20.

18. Catastrophe et autres..., op. cit., p. 54.

19. En attendant Godot, op. cit., p. 94.

20. La dernière bande, op. cit., pp. 7-8.

21. Catastrophe et autres..., op. cit., p. 72.

22. Ibid., p. 75/p. 79.

23. Fin de partie, Paris, Les Editions de Minuit, 1957; p. 15. 
despertarlo quedan resueltas al poco de comenzar la obra. Cuando éste dice: "Préparemoi, je vais me coucher" y Clov le responde: "Je viens de te lever"24. Nagg lleva un gorro de noche y Nell de encaje ${ }^{25}$. Al comenzar la obra, Clov también retira un trapo que recubre los cubos de basura en que están encerrados. Podemos afirmar, por lo tanto, que los tres acaban de levantarse.

El protagonista de Solo viste una larga camisa de noche blanca y zapatillas. Sus cabellos blancos en desorden nos inclinan a pensar que acaba de abandonar la cama ${ }^{26}$. Como ya hemos visto, P lleva bata y pijama. Sin embargo, ni en su aspecto, ni en la obra aparece ningún indicio que nos permita establecer el momento del día.

Los personajes A y B de Acte sans paroles II se visten y desvisten reproduciendo el momento de levantarse y de acostarse. El primero sale de su saco en camisa y se pone una chaqueta, un pantalón, un sombrero y un par de zapatos. Come parte de una zanahoria empezada, traslada su saco y el de su compañero y comienza a quitarse la ropa que lanza por el suelo, conservando su camisa. $Y$, finalmente, se introduce en su saco. Después sale B quien como su compañero, se coloca y se quita la misma ropa. Aunque éste manifiesta más esmero, ya que se la cepilla y, después de quitársela, la deja en un montón con sumo cuidado ${ }^{27}$. El trato que da a la ropa nos indica que es más ordenado y cuidadoso que su compañero.

Hay un caso en el que la ropa manifiesta los deseos e intenciones del personaje. Poco antes de acabar Fin de partie, Clov se presenta en escena con "Panama, veston de tweed, imperméable sur le bras, paraplui, valise"28. Con lo cual se nos da a entender que está a punto de realizar lo que ha estado intentando durante toda la obra, abandonar a Hamm.

Al final de En attendant Godot, Vladimir y Estragon manifiestan la posibilidad de ahorcarse en el árbol y como no tienen con qué, el segundo "dénoue la corde qui maintient son pantalon. Celui-ci, beaucoup trop large, lui tombe autour des chevilles"29 . Así se desarrolla el único caso en el que se llega a la provocación, con la intervención de una prenda.

Lo más característico del vestuario de los personajes beckettianos es, sin lugar a dudas, el sombrero, con todas las modalidades que éste presenta. Como hemos podido comprobar a lo largo de este punto, casi todos los personajes lo llevan. Tanto se usa que

24. Ibid., p. 18.

25. Ibid., p. 23/p 29.

26. Catastrophe et cutres..., op. cit., p. 29.

27. Comédie et actes divers op. cit., p. 106/p. 108

28. Fin de partie, op. cit., p. 110.

29. En attendant Godot, op. cit., p. 132. En Magazine littéraire, $\mathrm{n}^{\mathrm{0}} 231$, junio 1986, (p. 35), se recoge una carta de Beckett a Roger Blin, mientras éste preparaba la puesta en escena de En attendant Godot, instándole a que el actor Pierre Latour que se negaba a bajarse los pantalones, lo hiciera. En ella, el autor señala las razones de la importancia de este episodio. A continuación, reproducimos parte de la misma: "Quand aux rires qui pourraient saluer la chute complète, au grand dam de ce touchant tableau final, il n' y a absolument rien à y objeter, ils seraient du même ordre que les précédents. L'esprit de la pièce, dans la mesure oú elle en a, c'est que rien n'est plus grotesque que le tragique, et il faut l'exprimer jusqu'à la fin, et surtout à la fin. $J^{\prime}$ ai un tas d'autres raisons pour vouloir que ce jeu de scène ne soit pas escamoté, mais je vous en fait grâce. Soyez seulement assez gentil de le rétablir comme c'est indiqué dans le texte, et comme nous l'avions toujours prévu au cours des répétitions, et que le pantalon tombe complètement, autour des chévilles. Ça doit vous sembler stupide, mais pour moi c'est capital". 
Beckett llega a señalar su ausencia. Al caracterizar al personaje A de Catastrophe dice: "Tête nue" ${ }^{30}$. En general, juegan un papel bastante importante. Ya se ha señalado que ridiculizan, esconden los rostros y marcan el momento del día (nos referimos al gorro de noche de Nagg). En el apartado siguiente, vamos a ver cómo el bombín en $E n$ attendant Godot se convierte en accesorio.

\section{I.1. Prendas que funcionan como accesorios}

Los cuatro personajes de En attendant Godot llevan bombín. En muchos casos éste se emplea con otra finalidad distinta a la propiamente suya. Con ello, adquiere la categoría de accesorio.

Tout élément de costume peut devenir accesoire, dés qu'il joue un rôle particulier, indépendant des fonctions sémiologiques de l'habillement ${ }^{31}$.

Vladimir mira, repetidas veces, en el interior de su bombín, pasa la mano y "tape dessus comme pour en faire tomber quelque chose"32. ¿Qué es lo que busca?. No lo sabemos. La explicación la vamos a encontrar a partir del momento en que comienza a olvidarse de su sombrero y muestra interés por el de Lucky. Tras su extenso galimatías, se desvanece y mientras Vladimir se apropia de su sombrero. Lo contempla y mira en su interior, con el fin de cerciorarse que contrariamente a lo que le ocurre al suyo que está vacío, éste puede tener contenido o materia pensante. La identificación del bombín de Lucky con su capacidad de raciocinio queda confirmada por Pozzo. El discurso le hace sospechar que éste puede pensar y, por lo tanto, sublevarse y acabar con el dominio que ejerce sobre él. De ahí que arrebate el sombrero de Lucky a Vladimir y salte sobre él.

Pozzo. - Donnez-moi ça! (Il arrache le chapeau des mains de Vladimir, le jette par terre, saute dessus.) Comme ça il ne pensera plus!/ Vladimir. - Mais va-t-il pouvoir s'orienter?/Pozzo. —C'est moi qui l'orienterai. (Il donne des coups de pied à Lucky.) Debout! Porc! ${ }^{33}$.

En el segundo acto, Vladimir confirma que están en el mismo lugar que la víspera, al encontrar el sombrero de Lucky en el lugar donde lo había pisoteado Pozzo. Lo recoge, lo arregla y se lo coloca, entregando el suyo a Estragon. Éste se lo pone después de haberse quitado el suyo que entrega a su compañero. Iniciándose así una serie de intercambios de bombines entre ambos. Al final, Estragon se queda con su sombrero y

30. Catastrophe et autres..., op. cit., p. 71.

31. Kowzan, op. cit., p. 196.

32. En attendant Godot, op. cit., pp. 12-13/p. 50/p. 52.

33. Ibid., p. 62. 
Vladimir con el de Lucky. El suyo acaba en el suelo. Vladimir cree que ahora, con el sombrero de Lucky en su cabeza podrá pensar como él. Por eso le dice a Estragon: "On pourrait jouer à Pozzo et Lucky" y más tarde: "Dis-moi de penser" ${ }^{44}$.

¿Qué valor tiene el bombín como accesorio?. Es un instrumento que sirve para pasar el tiempo. Permite crear juegos como el intercambio de sombreros y, además, al identificarlo con la capacidad de pensar, proporciona otro pasatiempo: hablar. Es un elemento importante, dentro de la tendencia de Vladimir y Estragon a "amueblar" el tiempo de la espera. Pierre Brunel la hace extensiva a todos los personajes beckettianos:

...les personnages de Beckett tentent d'accélerer le Temps en le recouvrant par le temps de leurs conversations, de leurs histoires, de leurs jeux et pantomines, de leurs rencontres ${ }^{35}$.

De manera que a su función habitual como prenda de vestir, hay que añadir otra mucho más significativa en el teatro que analizamos, como acabamos de ver.

Los zapatos de Estragon son otro ejemplo de elemento del vestuario transformado en accesorio. Después que Vladimir mira en el interior de su sombrero, pasa la mano y lo golpea, aquél realiza lo mismo con uno de sus zapatos que acaba de quitarse.

Estragon, au prix d'un suprême effort, parvient à enlever sa chaussure. Il regarde dedans y promène sa main, la retourne, la secoue, cherche par terre s'il n'en est pas tombé quelque chose, ne trouve rien, passe sa main à nouveau dans sa chaussure, les yeux vagues ${ }^{36}$.

Vuelve a mirarlo en dos ocasiones más ${ }^{37}$. En la última de cllas coincide con Vladimir examinando su bombín. Al final del primer acto, se quita el otro zapato, coge los dos y "les dépose près de la rampe" ${ }^{38}$. En ese mismo lugar aparecen en el segundo acto, de la siguiente manera: "talons joints, bouts écartés". Vladimir se acerca hasta ellos "se baisse, en ramasse une, l'examine, la ranifle, la remet soigneusement à sa place"39 Estragon los coloca en ese lugar porque relaciona el vacío existente en su interior, cuando mira "ne trouve rien", con el reinante en la sala. Al desear escapar, sospechando que se acerca algún enemigo, Vladimir "l'amène vers la rampe" y le dice: "Là il n'y a personne. Sauve-toi par là"40.

Se quita un zapato, después el otro, los examina, pasa la mano por su interior, los coloca en la rampa... con ello, consigue que el tiempo de la espera vaya transcurriendo. Su compañero también los examina, como hemos señalado más arriba, y es consciente

\footnotetext{
34. Ibid., pp. 102-103.

35. BRUNEL, P. “Autour de Samuel Bcckett: devanciers, épigons et hérétiques” en La mort de Godot attente et évanescence au théâtre Albee, Beckett, Betti, Duras, Lorca, Tchékhov, Paris, Lettres modemes minard, 1970; p. 27.

36. En attendant Godot, op. cit., p. 12.

37. Ibid., p. $16 /$ pp. 50-51.

38. Ibid., p. 73.

39. Ibid., p. 79.

40. Ibid., p. 104
} 
de su valor como instrumento de pasatiempo. De ahí que proponga a Estragon colocárselos, con el fin de entretenerse.

Vladimir. —Si tu les essayais?/Estragon. —J'ai tout essayé./ Vladimir. - Je veux dire, les chaussures./ Estragon. - Tu crois?/ Vladimir. - Ça fera passer le temps. (Estragon hésite.) Je t'assure, ce sera une diversion./ Estragon. - Un délassement./ Vladimir. -Une distraction./ Estragon. —Un délassement./ Vladimir. - Essaic/ Estragon. —Tu m’aideras?./ Vladimir. -Bien sûr ${ }^{41}$.

Los zapatos apenas desempeñan su función habitual. Estragon permanece más tiempo descalzo que calzado. Son un instrumento de pasatiempo. Tienen, así pues, el mismo valor que el bombín.

El bolso de Winnie tiene la misma lectura. Está, sin embargo, más próximo al bombín que a los zapatos, ya que se identifica con la memoria y, por lo tanto, con su medio de expresión: la palabra. La protagonista de Oh les beaux jours va extrayendo infinidad de objetos de su bolso: un cepillo de dientes, un tubo de dentífrico, un espejo, un lápiz de labios, una caja de música... ${ }^{42}$. De la misma manera que va evocando los recuerdos del pasado. Con ello, consigue entretenerse y pasar el tiempo. Llegando incluso a hacer feliz su jornada. "Oh le beau jour encore que ça aura été, encore un!", dice al final de los dos actos ${ }^{43}$.

Estamos ante un signo visual cuyo valor o contenido corresponde a tres realidades materiales distintas: el bombín, los zapatos y el bolso. Es decir, un mismo signo responde a tres significantes distintos.

Hay otra prenda que sobrepasa los límites de su empleo habitual: el pañuelo. Hamm cubre su rostro con uno manchado de sangre, al comienzo y al final de Fin de partie $e^{44}$ Willie se asoma tras el montículo con su cabeza cubierta con esa misma prenda, también manchada de sangre ${ }^{45}$. En ambos casos, nos muestra el lamentable estado físico del personaje. La relación pañuclo/sangre se manificsta en otra ocasión: cuando el protagonista de Acte sans paroles I frota con él las tijeras con las que piensa acabar con su vida ${ }^{46}$. A veces, se relaciona con el estado anímico de los personajes y funciona como consuelo. Lucky llora y Pozzo, tendiendo su pañuelo a Estragon, le dice: "Consolez-le, puisque vous le plaignez" ${ }^{\prime 7}$.

Michel Haerdter recoge, en su artículo "S. Beckett répète Fin de partie", lo siguiente sobre el pañuelo de Hamm: "Quelqu'un s'aventure à demander [a Beckett] si ce

\footnotetext{
41. Jbid., pp. 96-97.

42. Oh les beaux jours suivi de..., op. cit., p. 13/p. 14/p. 19/pp. 46-47

43. Ibid., p. 56/p. 76

44. Fin de partie, op. cit., p. 15/p. 112.

45. Oh les beaux jours suivi de..., op. cit., p. 20

46. Comédie et actes divers, op. cit., p. 100.

47. En attendant Godot, op. cit., 43.
} 


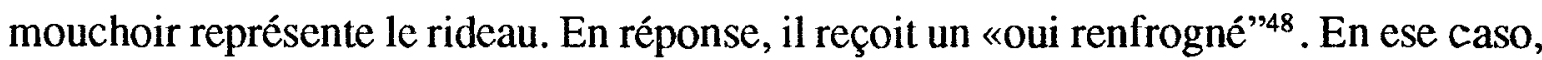
no sólo funciona como accesorio sino que llega incluso a convertirse en un elemento del decorado. En Fragment de théâtre II, tenemos otro ejemplo de ello. Al final de la obra, Bertrand "sort son mouchoir et l'approche timidement du visage de C"49. Tanto en un caso como en el otro, el rostro cubierto o descubierto significa el comienzo o final de la obra. Esto quiere decir que esta parte del cuerpo es de vital importancia. No es ex traño, por lo tanto, que haya personajes a los que sólo vemos su cara. Pensemos en F1, F2, H, el protagonista de Cette fois o en Winnie, en el segundo acto.

\section{MAQUILLAJE Y PEINADO}

Tadeusz Kowzan señala que la función del maquillaje es la de poner de relieve el rostro de los personajes y que "tandis que la mimique, grâce aux mouvements des muscles de la face, crée surtout des signes mobiles, le maquillage forme des signes qui ont un caractère plus durable" 50 .

El color del rostro de Clov y Hamm es muy rojo. El de Nagg y Nell es muy blanco ${ }^{51}$, mostrándose la palidez de unos seres de edad avanzada (son los padres de Hamm), encerrados en sendos cubos de basura e inmersos en un estado de inercia casi absoluta. Frente a los otros dos que, a pesar de sus dificultades físicas (el primero tiene problemas locomotrices y el segundo es inválido), llevan una existencia más o menos activa, gracias, en gran medida, al conflicto existente entre ambos, consistente en los deseos de Clov por abandonar a Hamm y en el afán de éste por impedirlo. La tensión que provoca esta situación queda reflejada en el color de sus rostros. Son seres que se exaltan en muchas ocasiones.

La expresividad de los rostros de Hamm y Clov, conseguida gracias al maquillaje, no la volvemos a ver en ningún otro personaje. Si éste aparece de nuevo es para resaltar una palidez cercana a lo inexpresivo. Es el caso de Krapp, "visage blanc"52, del Protagonista de Cette fois, "vieux visage blême" 53 y de F en Berceuse, "visage blanc sans expression" ${ }^{\prime 4}$.

Los rostros "sans âge" de F1, F2 y H H5 $^{55}$ la "tête basse" de P en Catastrophe contribuyen aún más a que podamos hablar de la falta de expresividad como algo frecuente en los rostros de los personajes beckettianos. Recordemos, asimismo, los amplios sombreros cubriendo la cara de muchos de ellos.

A veces, el maquillaje se extiende a otras partes del cuerpo, como, por ejemplo, las

\footnotetext{
48. Revue d'Esthétique, op. cit., p. 314.

49. Pas suivi de..., op. cit., p. 61.

50. Kowzan, op. cit., p. 191.

51. Fin de partie, op. cit., p. 13/p. 14; p. 23/p. 29

52. La dernière bande, op. cit., p. 8.

53. Catastrophe et autres..., op. cit., p. 9.

54. Ibid., p. 5.

55. Comédie et actes divers, op. cit., p. 9.

56. Catastrophe et autres..., op. cit., p. 72
} 
manos. Para Flo, Vi y Ru se indica: "Mains rendues aussi visibles que possible par le maquillage". Las tres aparecen sentadas en un banco:

Genre banc étroit sans dossier, juste assez long pour que puissent y tenir les trois femmes se touchant presque. Aussi peu visible que possible. A se demander sur quoi elles sont assises ${ }^{57}$.

Si se resaltan las manos que aparecen "jointes sur les genoux" 58 se debe a que, teniendo en cuenta que el banco apenas se aprecia, es la única manera de manifestar que los tres personajes están sentados. Lo mismo ocurre con las manos blancas de F que aparecen "serrant les bouts des accoudoirs" de la mecedora en la que está sentada ${ }^{59}$. El maquillaje facilita, por lo tanto, la localización de los personajes.

En cuanto a los cabellos, frente a personajes calvos como Pozzo y Willie hay otros de abundantes melenas. La calvicie del primero no se descubre hasta bien avanzado el primer acto, cuando tras quitarse el sombrero se observa que está completamente cal$v^{60}$. El "crâne chauve" de Willie aparece repetidas veces tras el montículo, en el que se encuentra atrapada su esposa ${ }^{61}$. Lucky $^{62}$, el Protagonista de Cette fois $^{63}$, los dos personajes de Impromptu d'Ohio ${ }^{64}$ y los cuatro de Quoi où ${ }^{65}$ tienen cabellos largos y todos ellos, añadiendo al Protagonista de Solo ${ }^{66}$ y exceptuando a Bam, Bem, Bim y Bom, de color blanco. Los de estos cuatro son grises como los de Krapp ${ }^{67}$, May ${ }^{68}$ y F de Berceuse ${ }^{69}$. El único personaje con el pelo rubio es Winnie ${ }^{70}$.

La existencia de calvicie, en algunos casos, y la frecuencia de los cabellos blancos y grises confirma el predominio de la edad avanzada entre los personajes. De ello hablaremos más adelante.

Otro rasgo muy significativo y común en varios personajes son los cabellos descuidados y en desorden. Ejemplo de ello son el personaje deSolo, Krapp, May y F de Berceuse. En el primer caso el protagonista de la obra acaba de levantarse de la cama, a su izquierda hay una lámpara y a su derecha un camastro. Aparece vestido con "longue chemise de nuit blanche" y "chaussettes blanches"71. En los demás se trata de personas desaliñadas. Krapp, por ejemplo, está además "mal rasé"72 y May lleva un "peignoir gris

\footnotetext{
57. Comédie et actes divers, op. cit., p. 43.

58. Ibid., p. 39.

59. Catastrophe et autres..., op. cit., p. 53.

60. En attendant Godot, op. cit., p. 46.

61. Oh les beaux jours suivi de..., op. cit., p. 19/p. 29/p. 55 .

62. En attendant Godot, op. cit., p. 45.

63. Catastrophe et autres..., op. cit., p. 9.

64. Ibid., p. 59/p. 60 .

65. Ibid., p. 85.

66. Ibid., p. 29.

67. La dernière bande, op. cit., p. 8

68. Pas suivi de..., op. cit., p. 7.

69. Catastrophe et autres..., op. cit., p. 53.

70. Oh les beaux jours suivi de... op. cit., p. 11

71. Catastrophe et autres..., op. cit., p. 29.

72. La dernière bande, op. cit., p. 8.
} 
dépenaillé"73 . La misma explicación podemos dar para los personajes que llevan cabellos largos, citados más arriba.

Teniendo en cuenta la escasa preocupación por vestir bien y el poco cuidado que se presta al peinado, anotaremos el descuido del aspecto físico como característica de buen número de personajes.

Winnie es una excepción a lo afirmado anteriormente. Sus hombros y brazos aparecen desnudos, gracias a su "corsage très décolleté". Lleva collar, se limpia e inspecciona los dientes con ayuda de un espejo, se pinta los labios, se arregla las uñas ${ }^{74}$ ... Se preocupa por su aspecto físico, llegando incluso a la coquetería. Es el único personaje del que se puede afirmar esto. Su aseo y cuidado contrasta con el desaliño de los demás.

\section{LA EDAD}

En muchos casos no se nos señala la edad de los personajes, ni se aporta dato alguno que nos permita adivinarla. En otros hay un deseo expreso de borrar la huella de los años. F1, F2 y H de Comédie no manifiestan ninguna, son "visages sans âge"7s. El espectador carece de esta información, surgiendo la ambigüedad temporal en los rostros. En Catastrophe, M, A y P son de "âge et physique indifférents" " . Su edad se convierte en algo sin importancia y secundario.

Sin embargo, encontramos personajes de los que podemos llegar a conocerla de manera exacta o, al menos, aproximada. Pozzo y Krapp la expresan ellos mismos. El primero dice:

Il y aura bientôt soixante ans que ça dure... (il calcule mentalement)... oui, bientôt soixante. (Se redressant fièrement.) On ne me les donnerait pas, n'est-ce pas? (Vladimir regarde Lucky). A côté de lui j’ai l'air d'un jeune homme, non?77.

Krapp escucha una cinta grabada hace 30 años, cuando tenía 39. Por lo tanto, su edad exacta será de 69 años $^{78}$. Por mediación de otro personaje sospechamos los años que puede tener Vladimir y conocemos los de May. Pozzo realiza la siguiente pregunta a Vladimir que no da ninguna respuesta: "Quel âge avez-vous, sans indiscrétion? (Silence) Soixante-dix?..." ." "Quel âge ai-je... déjà?", se pregunta la protagonista de Pas , a lo que responde V. (la voz de su madre): "La quarantaine"80.

\footnotetext{
73. Pas suivi de..., op. cit., p. 7.

74. Oh les beaux jours suivi de..., op. cit., p. 11/pp. 13-14/p. 19/pp. 48-51.

75. Comédie et actes divers, op. cit., p. 9.

76. Catastrophe et autres..., op. cit., pp. 71-72.

77. En attendant Godot, op. cit., p. 45.

78. La dernière bande, op. cit., p. 13/p. 27.

79. En attendant Godot, op. cit., p. 37.

80. Pas suivi de..., op. cit., p. 10.
} 
En las acotaciones escénicas de Berceuse se dice de F: "Viellie avant 1'heure" 11 Y antes de que éstas se realicen en Oh les beaux jours, Beckett señala la edad de sus personajes: Winnie 50 años y Willie $60^{82}$. Como ya hemos visto al hablar del peinado, la calvicie y los cabellos blancos y grises nos indican que abundan los personajes de edad avanzada. En el caso de Lucky hay que añadir el comentario que hace Pozzo comparando su edad con la de él ${ }^{83}$.

En todos los casos que sabemos la edad exacta o aproximada, a excepción de May, con 40 años, se iguala y se supera la barrera de los 50 . Se trata, por lo tanto, de personas de edad avanzada. Cuando llegamos a ella por algún rasgo de su aspecto físico, la conclusión es la misma. Hay que insistir de todas formas en que no conocemos la edad de muchos personajes y que en otros hay deseos expresos de que no se perciba.

\section{DEFICIENCIAS FÍSICAS}

Los personajes beckettianos sufren las siguientes deficiencias físicas: ceguera, mala vista, invalidez, dificultades locomotrices y sordera.

Son ciegos Hamm y A de Fragment de théâtre I y Pozzo, a partir del segundo acto. Los tres cuentan con la ayuda de un segundo personaje que hace las veces de lazarillo. El tercero de ellos con la de Lucky, ambos permanecen unidos por una cuerda que es mucho más corta en el segundo acto, para facilitar los desplazamientos de Pozzo. Debido a su reciente ceguera no es muy diestro y se mueve con mucha dificultad. Al poco de entrar en el escenario choca con Lucky, provocando la caida de los dos ${ }^{84}$. Hamm que lleva unas gafas para cubrir sus ojos invidentes, es conducido por Clov ${ }^{85}$. Además, se sirve de la vista de éste para que le cuente lo que épno puede ver. En numerosas ocasiones le pide que mire y le explique lo que observa a través de las ventanas del escenario. A es un ciego que gana su vida cantando en la esquina de una calle. Se desplaza gracias a la ayuda de B quien se compromete a describirle lo que va viendo, a cambio de que empuje su silla de ruedas ${ }^{86}$.

Krapp es miope, aunque no lleva gafas. Cuando mira un objeto: una cinta, un plátano, una caja... siempre lo hace "de tout près"87. En cl caso de Winnie ocurre algo parecido. Lleva gafas, pero éstas no le sirven para leer la inscripción que aparece en el mango de su cepillo de dientes. Se ve obligada a utilizar una lupa, además de las gafas: "ramasse la brosse à dents et en examine le manche avec la loupe" 88 . El personaje B de Fragment de théâtre I, lleva una lente ${ }^{89}$.

81. Catastrophe et autres..., op. cit., p. 53.

82. Oh les beaux jours suivi de..., op. cit., p. 10.

83. En attendant Godot, op. cit., p. 45.

84. Ibid., p. 108.

85. Fin de partie, op. cit., p. 16/p. 41/pp. 85-88/p. 100.

86. Pas suivi de..., op. cit., pp. 27-28.

87. La dernière bande, op. cit., p. 9/p. 11.

88. Oh les beaux jours suivi de..., op. cit., p. 23.

89. Pas suivi de... op. cit., p. 31. 
A la ceguera de Hamm hay que añadir su invalidez, que lo tiene postrado en una silla de ruedas. Para desplazarse se ve obligado a recurrir a $\operatorname{Clov}^{90} \mathrm{o}$ al bichero. Cuando, al final de la obra, cree que éste le va a abandonar definitivamente "essaie de déplacer le fauteuil en prenant appui sur la gaffe" "91. El personaje B de Fragment de théâtre I quien, como Hamm, es paralítico, utiliza los mismos medios para desplazarse. Le dice a su compañero ciego: "si voulez me promener j'essaierai de vous décrire la scène, au fur et à mesure" 92 . Al comenzar la obra entra en una silla de ruedas "qu' il fait avancer au moyen d'une perche" 93 .

Si Hamm no puede levantarse, Clov no puede sentarse. Tiene dificultades locomotrices que le obligan a una "démarche raide et vacillante". En una ocasión dice: "J'ai mal aux jambes" ${ }^{\prime 94}$. No es el único que tiene estos problemas. Parecida manera de andar la vemos en Vladimir: "à petits pas raides, les jambes écartées"95. Al comienzo de En attendant Godot, Estragon que se encuentra sentado, al incorporarse, lo hace con serias dificultades ${ }^{96}$. No debemos olvidar la "démarche laborieuse" de Krapp ${ }^{97}$, ni tampoco la torpeza de movimientos del personaje A de Acte sans paroles $I^{98}$.

El único personaje con problemas de oído es Krapp ${ }^{99}$. Contrariamente a lo que cabría esperar debido a las dificultades físicas generalizadas, a este órgano no le afectan y es imprescindible para algunos personajes. $Y$ ello es consecuencia de la "perte ou de l'abandon, quelque fois volontaire, des autres sens, en premier lieu de la vue"100. Ya hemos visto que Hamm necesita de Clov para que éste le explique lo que sus ojos no pueden ver. Convirtiéndose para él el oído en algo importantísimo. También lo es para A de Fragment de théâtre I:

A s'arrête de gratter, tourne la tête vers la coulisse droite, écoute... A se remet à gratter. Il s’arrête de nouveau, tourne la tête vers la coulisse droite, écoute. Entre B dans un fauteuil roulant... ${ }^{101}$.

Las deficiencias fisicas se localizan fundamentalmente en dos partes concretas del cuerpo: la vista y las extremidades inferiores. Predominando, por una parte, la ceguera o las dificultades visuales y, por otra, la invalidez o problemas motrices. En ambos casos la consecuencia más generalizada es la misma: la reducción de las posibilidades de desplazamiento, llegándose hasta la inmovilización.

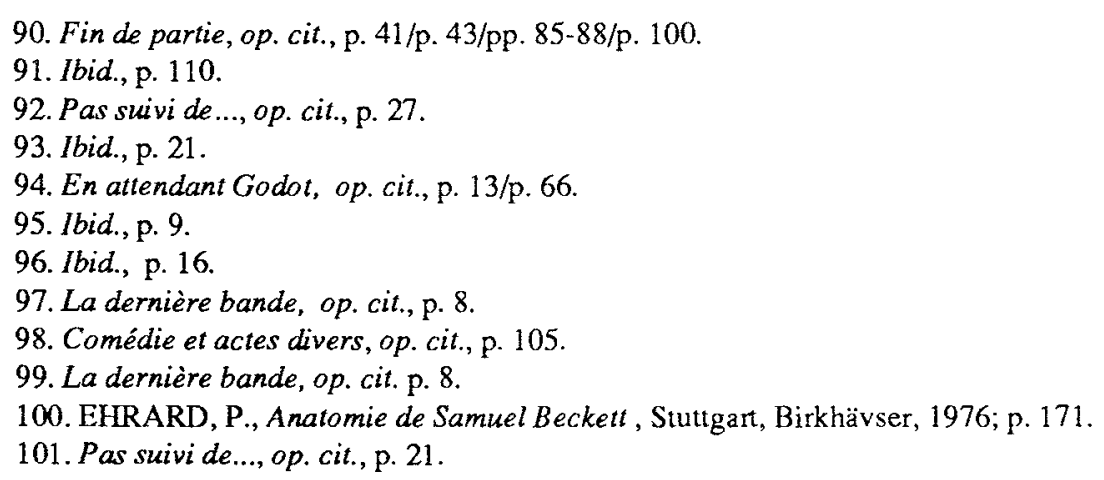


Estamos ante seres limitados físicamente que, en muchos casos, se sienten impotentes. Recordemos a Hamm tratando de desplazarse con el bichero. Siempre necesitan de algo o de alguien, ya que no son autosuficientes.

\section{CONCLUSIONES}

Los personajes del teatro de S. Beckett no visten bien, llevan prendas de escasa calidad, en mal estado, sobre todo sucias y no conjuntadas. Estas tienden a despersonalizarlos y uniformarlos, ya que borran los posibles rasgos diferenciadores de sus cuerpos y, en ocasiones, sirven para ridiculizarlos. En general, todos visten de manera más o menos parecida. El sombrero, por ejemplo, es prenda común a casi todos. Por otra parte, es escasa la información que nos aporta el vestuario. Tan solo, gracias a él, podemos saber en qué momento del día nos encontramos. Sobre todo, si se trata del momento inmediatamente anterior a acostarse o de levantarse: son frecuentes los personajes en pijama o con gorros de noche.

El maquillaje apenas existe. Si aparece no es para poner de relieve y resaltar los rostros de los personajes sino para hacerlos inexpresivos. En algunos casos, se maquilla las manos para facilitar la localización y postura de los personajes rodeados por la obscuridad. Los cabellos suelen ser largos, en desorden y poco cuidados. Predominan los de color blanco y gris y existen personajes calvos. No es extraño, ya que la mayoría iguala o supera la barrera de los 50 años. A veces, existe el deseo de borrar la huella de los años. En otras ocasiones este hecho no tiene ninguna importancia.

Además de ser de edad avanzada, sufren deficiencias físicas. Estas se concentran, sobre todo, en la vista y extremidades inferiores. Encontramos a ciegos y a otros con mala vista. Así como a inválidos o personajes que se mueven con gran dificultad. Son seres imposibilitados que muchas veces se ven impotentes y necesitan la ayuda de otro para desplazarse. Aparecen las gafas obscuras, para disimular la ceguera, las de aumento, las sillas de ruedas y varas, con las que se ayudan los parapléjicos, cuando no cuentan con el auxilio de alguien.

Haciendo abstracción de todo lo anterior podemos establecer el personajes tipo que presentaría los siguentes rasgos. Se trata de una persona de edad avanzada y con frecuencia con alguna deficiencia física que pone poco interés en vestir bien, escasamente maquillada y que descuida sus cabellos. Su aspecto físico no sirve para individualizarlos, sino para todo lo contrario. Su análisis nos descubre cuerpos poco definidos y escasamente expresivos. En el sentido de que, en muchos casos, su expresividad es la carencia de tal.

Somos conscientes de que el modelo presentado no se ajusta a todos los casos. Recordemos, por ejemplo a la protagonista de Oh les beaux jours que presenta formas de vestir elegantes y raya la coquetería.

El objetivo primordial del artículo era el de analizar el aspecto físico de los personajes del teatro beckettiano. Sin embargo, al aplicar el método de Kowzan hemos constatado que para nuestro caso se requería la introducción de dos sistemas de signos más: la edad y las deficiencias físicas. Con lo cual creemos haber hecho una pequeña contribución metodológica. La aplicación de estos dos nuevos sistemas en otros autores determinará el que se incluyan o no dentro del sistema de signos del aspecto externo 
establecido por Kowzan. En todo caso dejamos vía libre para que se tengan o no en cuenta en estudios posteriores.

\section{Ediciones utilizadas:}

- En attendant Godot, París, Les Editions de Minuit, 1952.

- Fin de partie, París, Les Editions de Minuit., 1957.

- La dernière bande, París, Les Editions de Minuit, 1959.

- Oh les beaux jours suivi de Pas moi, París, Les Editions de Minuit,1963-1974.

- Comédie et actes divers. Va-et-vient, Acte sans paroles I et II, Souffle, París, Les Editions de Minuit, 1972.

- Pas suivi de quatre esquisses (Fragment de théâtre I et II), París, Les Editions de Minuit, 1978.

- Catastrophe et autres dramaticules. Cette fois, Solo, Berceuse, Impromptu d'Ohio, Quoi où, París, Les Editions de Minuit, 1986.

Producción teatral beckettiana, por orden cronológico de escritura ${ }^{102}$ y distribución de los personajes:

- 1952, - En attendant Godot: Vladimir, Estragon, Pozzo y Lucky.

-1956, - Acte sans paroles I: Protagonista.

-1957, - Fin de partie: Hamm, Clov, Nagg y Nell.

-1958, - La dernière bande: Krapp.

-1959, - Acte sans paroles II: A y B.

-1960, - Fragment de théâtre I: A y B.

- Fragment de théâtre II: Bertrand, Morvan y C.

-1961, - Oh les beaux jours: Winnie y Willie.

-1963, - Comédie: F2, H y F1.

-1965, - Va-et-vient: Flo, Vi y Ru.

-1969, - Souffle ${ }^{103}$.

-1972, — Pas moi: Boca y Auditor.

-1974, - Cette fois: Protagonista.

-1975, - Pas ${ }^{104}$ : May.

-1980, - Solo: Protagonista.

-1981, - Impromptu d'Ohio: Lector y Entendedor.

- Berceuse: F.

-1982, - Catastrophe: M, A y P.

-1983, - Quoi où: Bam, Bem, Bim y Bom.

102. FOURNIER, E., "Liste chronologique des oeuvres", en Revue d'Esthétique. Samuel Beckett, op. cit., pp. 416-422. 